Article

\title{
Double Controlled Metric Type Spaces and Some Fixed Point Results
}

\author{
Thabet Abdeljawad ${ }^{1}$ (D), Nabil Mlaiki ${ }^{1}$, Hassen Aydi ${ }^{2, *}$ (D) and Nizar Souayah ${ }^{3}$ \\ 1 Department of Mathematics and General Sciences, Prince Sultan University, P.O. Box 66833, Riyadh 11586, \\ Saudi Arabia; tabdeljawad@psu.edu.sa (T.A.); nmlaiki@psu.edu.sa (N.M.) \\ 2 Department of Mathematics, College of Education in Jubail, Imam Abdulrahman Bin Faisal University, \\ P.O. Box 12020, Jubail 31961, Saudi Arabia \\ 3 Department of Natural Sciences, Community College Al-Riyadh, King Saud University, Riyadh 4545, \\ Saudi Arabia; nizar.souayah@yahoo.fr \\ * Correspondence: hmaydi@iau.edu.sa or hassen.aydi@isima.rnu.tn; Tel.: +966-530894964
}

Received: 12 November 2018 ; Accepted: 7 December 2018; Published: 12 December 2018

Abstract: In this article, in the sequel of extending $b$-metric spaces, we modify controlled metric type spaces via two control functions $\alpha(x, y)$ and $\mu(x, y)$ on the right-hand side of the $b$-triangle inequality, that is,

$$
d(x, y) \leq \alpha(x, z) d(x, z)+\mu(z, y) d(z, y), \text { for all } x, y, z \in X
$$

Some examples of a double controlled metric type space by two incomparable functions, which is not a controlled metric type by one of the given functions, are presented. We also provide some fixed point results involving Banach type, Kannan type and $\phi$-nonlinear type contractions in the setting of double controlled metric type spaces.

Keywords: fixed point; a double controlled metric type; extended $b$-metric space

MSC: 47H10, 54H25

\section{Introduction}

One of the generalizations of metric spaces was studied by Bakhtin [1] and Czerwik [2] who introduced the notion of $b$-metric spaces. Since then, many authors obtained several fixed point results for single valued and multivalued operators in the setting of $b$-metric spaces, for instance, see [3-16]. Among the generalizations of $b$-metric spaces, we cite the work of Kamran et al. [17] (see also [18-21]) who introduced extended $b$-metric spaces by controlling the triangle inequality rather than using control functions in the contractive condition. Proving extensions of Banach contraction principle from metric spaces to b-metric spaces and hence to controlled metric type spaces is useful to prove existence and uniqueness theorem for different types of integral and differential equations. Some nice applications can be found for example in the recent article [22]. In fact, the authors in [17] gave a slightly modified application of a proven fixed point result. However, finding serious applications to integral equations and dynamical systems is still of interest. In this article, we have been only motivated theoretically to relax the triangle inequality of $b$-metric spaces by using two controlled functions rather than using one.

Definition 1. [17] Given a function $\theta: X \times X \rightarrow[1, \infty)$, where $X$ is a nonempty set. The function $d$ : $X \times X \rightarrow[0, \infty)$ is called an extended b-metric if

1. $d(x, y)=0 \Longleftrightarrow x=y$, 
2. $\quad d(x, y)=d(y, x)$,

3. $\quad d(x, y) \leq \theta(x, y)[d(x, z)+d(z, y)]$,

for all $x, y, z \in X$.

Recently, Mlaiki et al. [23] generalized the notion of $b$-metric spaces.

Definition 2. [23] Given $\alpha: X \times X \rightarrow[1, \infty)$, where $X$ is nonempty. Let $\rho: X \times X \rightarrow[0, \infty)$. Suppose that ( $\rho 1) \rho(u, v)=0$ if and only if $u=v$,

( 22$) \rho(u, v)=\rho(v, u)$,

( $\rho 3) \rho(u, v) \leq \alpha(u, w) \rho(u, w)+\alpha(w, v) \rho(w, v)$,

for all $u, v, w \in X$. Then, $\rho$ is called a controlled metric type and $(X, \rho)$ is called a controlled metric type space.

Now, we introduce a more general $b$-metric space.

Definition 3. Given non-comparable functions $\alpha, \mu: X \times X \rightarrow[1, \infty)$. If $q: X^{2} \rightarrow[0, \infty)$ satisfies

(q1) $q(u, v)=0 \Longleftrightarrow u=v$,

(q2) $q(u, v)=q(v, u)$,

(q3) $q(u, v) \leq \alpha(u, w) q(u, w)+\mu(w, v) q(w, v)$,

for all $u, v, w \in X$. Then, $q$ is called a double controlled metric type by $\alpha$ and $\mu$.

Remark 1. A controlled metric type is also a double controlled metric type when taking the same function(s). The converse is not true in general (see Examples 1 and 2).

Example 1. Let $X=[0, \infty)$. Define $q$ by

$$
q(x, y)= \begin{cases}0, & \Longleftrightarrow x=y, \\ \frac{1}{x}, & \text { if } x \geq 1 \text { and } y \in[0,1), \\ \frac{1}{y}, & \text { if } y \geq 1 \text { and } x \in[0,1), \\ 1, & \text { if not. }\end{cases}
$$

Consider $\alpha, \mu: X^{2} \rightarrow[1, \infty)$ as

$$
\alpha(x, y)=\left\{\begin{array}{ll}
x, & \text { if } x, y \geq 1, \\
1, & \text { if not, }
\end{array} \text { and } \mu(x, y)= \begin{cases}1, & \text { if } x, y<1, \\
\max \{x, y\}, & \text { if not. }\end{cases}\right.
$$

The conditions ( $q 1)$ and ( $q 2)$ hold. We claim that ( $q 3)$ is satisfied.

(i): When $z=x$ or $z=y$, (q3) holds.

(ii): Otherwise, first (q3) is verified in the case that $x=y$. Consider the case that $x \neq y$, hence we get that $x \neq y \neq z$. In the subcases ( $x \geq 1$ and $y \in[0,1)$ ) and ( $y \geq 1$ and $x \in[0,1)$ ), it is easy to see that (q3) holds. Here, we have:

Subcase 1: $x, y \geq 1$.

If $z \geq 1$, (q3) holds. While, if $z \in[0,1)$, we have

$$
1 \leq \frac{1}{x}+y \cdot \frac{1}{y}
$$

that is, (q3) is satisfied.

Subcase 2: $x, y<1$.

If $z \in[0,1)$, (q3) holds. While, if $z \geq 1$, we have

$$
1 \leq \frac{1}{z}+z \cdot \frac{1}{z}
$$


that is, (q3) is verified. We deduce that $q$ is a double controlled metric type.

On the other hand, we have

$$
q\left(0, \frac{1}{2}\right)=1>\frac{2}{3}=\frac{1}{3}+\frac{1}{3}=\alpha(0,3) q(0,3)+\alpha\left(3, \frac{1}{2}\right) q\left(3, \frac{1}{2}\right) .
$$

This leads us to say that $q$ is not an extended $b$-metric when considering the same function $\mu=\alpha$.

Example 2. Let $X=\{0,1,2\}$. Consider the double controlled metric type $q$ defined by

\begin{tabular}{|c|c|c|c|}
\hline$q(x, y)$ & 0 & 1 & 2 \\
\hline 0 & 0 & 1 & $\frac{1}{2}$ \\
\hline 1 & 1 & 0 & $\frac{2}{5}$ \\
\hline 2 & $\frac{1}{2}$ & $\frac{2}{5}$ & 0 \\
\hline
\end{tabular}

Given $\alpha$ and $\mu$ as

\begin{tabular}{|c|c|c|c|}
\hline$\alpha(x, y)$ & 0 & 1 & 2 \\
\hline 0 & 1 & $\frac{11}{10}$ & 1 \\
\hline 1 & $\frac{11}{10}$ & 1 & $\frac{5}{8}$ \\
\hline 2 & 1 & $\frac{5}{8}$ & 1 \\
\hline
\end{tabular}

and

\begin{tabular}{|c|c|c|c|}
\hline$\mu(x, y)$ & 0 & 1 & 2 \\
\hline 0 & 1 & $\frac{11}{10}$ & $\frac{3}{2}$ \\
\hline 1 & $\frac{11}{10}$ & $\frac{3}{2}$ & 1 \\
\hline 2 & $\frac{3}{2}$ & $\frac{5}{4}$ & 1 \\
\hline
\end{tabular}

Note that

$$
q(0,1)>\alpha(0,2) q(0,2)+\alpha(2,1) q(2,1) .
$$

Thus, $q$ is not a controlled metric type for the function $\alpha$.

The topological concepts as continuity, convergent and Cauchy on double controlled metric type spaces are given in the following.

Definition 4. Let $(X, q)$ be a double controlled metric type space by one or two functions.

(1) The sequence $\left\{u_{n}\right\}$ is convergent to some $u$ in $X$, if for each positive $\varepsilon$, there is some integer $N_{\varepsilon}$ such that $q\left(u_{n}, u\right)<\varepsilon$ for each $n \geq N_{\varepsilon}$. It is written as $\lim _{n \rightarrow \infty} u_{n}=u$.

(2) The sequence $\left\{u_{n}\right\}$ is said Cauchy, if for every $\varepsilon>0, q\left(u_{n}, u_{m}\right)<\varepsilon$ for all $m, n \geq N_{\varepsilon}$, where $N_{\varepsilon}$ is some integer.

(3) $(X, q)$ is said complete if every Cauchy sequence is convergent.

Definition 5. Let $(X, q)$ be a double controlled metric type space by either one function or two functions-for $u \in X$ and $k>0$.

(i) We define $\mathcal{B}(u, k)$ as

$$
\mathcal{B}(u, k)=\{y \in X, q(u, y)<k\}
$$

(ii) The self-map $T$ on $X$ is said to be continuous at $u$ in $X$ if for all $\delta>0$, there exists $k>0$ such that $T(\mathcal{B}(u, k)) \subseteq \mathcal{B}(T u, \delta)$.

Note that if $T$ is continuous at $u$ in $(X, q)$, then $u_{n} \rightarrow u$ implies that $T u_{n} \rightarrow T u$ when $n$ tends to $\infty$.

In this paper, we present some fixed point theorems in double controlled metric type spaces. The first one is the related Banach contraction principle. The second one concerns with a nonlinear case involving a function $\phi$ satisfying suitable conditions. The last one is the related Kannan type result. The given concepts and theorems are illustrated by some examples.

\section{Main Results}

Our first fixed point result is the following: 
Theorem 1. Let $(X, d)$ be a complete double controlled metric type space by the functions $\alpha, \mu: X \times X \rightarrow$ $[1, \infty)$. Suppose that $T: X \rightarrow X$ satisfies

$$
q(T x, T y) \leq k q(x, y)
$$

for all $x, y \in X$, where $k \in(0,1)$. For $u_{0} \in X$, choose $u_{n}=T^{n} u_{0}$. Assume that

$$
\sup _{m \geq 1} \lim _{i \rightarrow \infty} \frac{\alpha\left(u_{i+1}, u_{i+2}\right)}{\alpha\left(u_{i}, u_{i+1}\right)} \mu\left(u_{i+1}, u_{m}\right)<\frac{1}{k} .
$$

In addition, for each $u \in X$, suppose that

$$
\lim _{n \rightarrow \infty} \alpha\left(u, u_{n}\right) \text { and } \lim _{n \rightarrow \infty} \mu\left(u_{n}, u\right) \text { exist and are finite. }
$$

Then, T has a unique fixed point.

Proof. Consider the sequence $\left\{u_{n}=T^{n} u_{0}\right\}$ in $X$ that satisfies the hypothesis of the theorem. By using label (1), we get

$$
q\left(u_{n}, u_{n+1}\right) \leq k^{n} q\left(u_{0}, u_{1}\right) \text { for all } n \geq 0 .
$$

Let $n, m$ be integers such that $n<m$. We have

$$
\begin{aligned}
q\left(u_{n}, u_{m}\right) & \leq \alpha\left(u_{n}, u_{n+1}\right) q\left(u_{n}, u_{n+1}\right)+\mu\left(u_{n+1}, u_{m}\right) q\left(u_{n+1}, u_{m}\right) \\
& \leq \alpha\left(u_{n}, u_{n+1}\right) q\left(u_{n}, u_{n+1}\right)+\mu\left(u_{n+1}, u_{m}\right) \alpha\left(u_{n+1}, u_{n+2}\right) q\left(u_{n+1}, u_{n+2}\right) \\
& +\mu\left(u_{n+1}, u_{m}\right) \mu\left(u_{n+2}, u_{m}\right) q\left(u_{n+2}, u_{m}\right) \\
& \leq \alpha\left(u_{n}, u_{n+1}\right) q\left(u_{n}, u_{n+1}\right)+\mu\left(u_{n+1}, u_{m}\right) \alpha\left(u_{n+1}, u_{n+2}\right) q\left(u_{n+1}, u_{n+2}\right) \\
& +\mu\left(u_{n+1}, u_{m}\right) \mu\left(u_{n+2}, u_{m}\right) \alpha\left(u_{n+2}, u_{n+3}\right) q\left(u_{n+2}, u_{n+3}\right) \\
& +\mu\left(u_{n+1}, u_{m}\right) \mu\left(u_{n+2}, u_{m}\right) \mu\left(u_{n+3}, u_{m}\right) q\left(u_{n+3}, u_{m}\right) \\
& \leq \cdots \\
& \leq \alpha\left(u_{n}, u_{n+1}\right) q\left(u_{n}, u_{n+1}\right)+\sum_{i=n+1}^{m-2}\left(\prod_{j=n+1}^{i} \mu\left(u_{j}, u_{m}\right)\right) \alpha\left(u_{i}, u_{i+1}\right) q\left(u_{i}, u_{i+1}\right) \\
& +\prod_{k=n+1}^{m-1} \mu\left(u_{k}, u_{m}\right) q\left(u_{m-1}, u_{m}\right) \\
& \leq \alpha\left(u_{n}, u_{n+1}\right) k^{n} q\left(u_{0}, u_{1}\right)+\sum_{i=n+1}^{m-2}\left(\prod_{j=n+1}^{i} \mu\left(u_{j}, u_{m}\right)\right) \alpha\left(u_{i}, u_{i+1}\right) k^{i} q\left(u_{0}, u_{1}\right) \\
& +\prod_{i=n+1}^{m-1} \mu\left(u_{i}, u_{m}\right) k^{m-1} q\left(u_{0}, u_{1}\right) \\
& \leq \alpha\left(u_{n}, u_{n+1}\right) k^{n} q\left(u_{0}, u_{1}\right)+\sum_{i=n+1}^{m-2}\left(\prod_{j=n+1}^{i} \mu\left(u_{j}, u_{m}\right)\right) \alpha\left(u_{i}, u_{i+1}\right) k^{i} q\left(u_{0}, u_{1}\right) \\
& +\left(\prod_{i=n+1}^{m-1} \mu\left(u_{i}, u_{m}\right)\right) k^{m-1} \alpha\left(u_{m-1}, u_{m}\right) q\left(u_{0}, u_{1}\right) \\
& =\alpha\left(u_{n}, u_{n+1}\right) k^{n} q\left(u_{0}, u_{1}\right)+\sum_{i=n+1}^{m-1}\left(\prod_{j=n+1}^{i} \mu\left(u_{j}, u_{m}\right)\right) \alpha\left(u_{i}, u_{i+1}\right) k^{i} q\left(u_{0}, u_{1}\right) \\
& \alpha\left(u_{n}, u_{n+1}\right) k^{n} q\left(u_{0}, u_{1}\right)+\sum_{i=n+1}^{m-1}\left(\prod_{j=0}^{i} \mu\left(u_{j}, u_{m}\right)\right) \alpha\left(u_{i}, u_{i+1}\right) k^{i} q\left(u_{0}, u_{1}\right) .
\end{aligned}
$$


We used $\alpha(x, y) \geq 1$. Let

$$
S_{p}=\sum_{i=0}^{p}\left(\prod_{j=0}^{i} \mu\left(u_{j}, u_{m}\right)\right) \alpha\left(u_{i}, u_{i+1}\right) k^{i}
$$

Hence, we have

$$
q\left(u_{n}, u_{m}\right) \leq q\left(u_{0}, u_{1}\right)\left[k^{n} \alpha\left(u_{n}, u_{n+1}\right)+\left(S_{m-1}-S_{n}\right)\right] .
$$

The ratio test together with (2) imply that the limit of the real number sequence $\left\{S_{n}\right\}$ exits, and so $\left\{S_{n}\right\}$ is Cauchy. Indeed, the ration test is applied to the term $a_{i}=\left(\prod_{j=0}^{i} \mu\left(u_{j}, u_{m}\right)\right) \alpha\left(u_{i}, u_{i+1}\right)$. Letting $n, m$ tend to $\infty$ in label (5) yields

$$
\lim _{n, m \rightarrow \infty} q\left(u_{n}, u_{m}\right)=0,
$$

so the sequence $\left\{u_{n}\right\}$ is Cauchy. Since $(X, q)$ is a complete double controlled metric type space, there exists some $\xi \in X$ such that

$$
\lim _{n \rightarrow \infty} q\left(u_{n}, \xi\right)=0
$$

We claim that $T \xi=\xi$. By $(q 3)$, we have

$$
q\left(\xi, u_{n+1}\right) \leq \alpha\left(\xi, u_{n}\right) q\left(\xi, u_{n}\right)+\mu\left(u_{n}, u_{n+1}\right) q\left(u_{n}, u_{n+1}\right) .
$$

Using (3) and (6), we get that

$$
\lim _{n \rightarrow \infty} q\left(\xi, u_{n+1}\right)=0
$$

By (1), we have

$$
\begin{aligned}
q(\xi, T \xi) & \leq \alpha\left(\xi, u_{n+1}\right) q\left(\xi, u_{n+1}\right)+\mu\left(u_{n+1}, T \xi\right) q\left(u_{n+1}, T \xi\right) \\
& \leq \alpha\left(u, u_{n+1}\right) q\left(\xi, u_{n+1}\right)+k \mu\left(u_{n+1}, T \xi\right) q\left(u_{n}, \xi\right) .
\end{aligned}
$$

Using (3) and (7), we get at the limit $q(\xi, T \xi)=0$, that is, $T \xi=\xi$. Let $\eta$ in $X$ be such that $T \eta=\eta$ and $\xi \neq \eta$. We have

$$
0<q(\xi, \eta)=q(T \xi, T \xi) \leq k q(\xi, \eta) .
$$

It is a contradiction, so $\xi=\eta$. Hence, $\xi$ is the unique fixed point of $T$.

Remark 2. The assumption (3) in Theorem 1 above can be replaced by the assumptions that the mapping $T$ and the double controlled metric $d$ are continuous. Indeed, when $u_{n} \rightarrow \xi$, then $T u_{n} \rightarrow T \xi$ and hence we have

$$
\lim _{n \rightarrow \infty} q\left(T u_{n}, T \xi\right)=0=\lim _{n \rightarrow \infty} q\left(T u_{n+1}, T \xi\right)=q(\xi, T \xi)
$$

and hence $T \xi=\xi$.

Theorem 1 is illustrated by the following examples.

Example 3. We endow $X=\{0,1,2\}$ by the following double controlled metric type

\begin{tabular}{|c|c|c|c|}
\hline$q(x, y)$ & 0 & 1 & 2 \\
\hline 0 & 0 & 1 & $\frac{2}{5}$ \\
\hline 1 & 1 & 0 & $\frac{6}{25}$ \\
\hline 2 & $\frac{2}{5}$ & $\frac{6}{25}$ & 0 \\
\hline
\end{tabular}


Given $\alpha$ and $\mu$ as

\begin{tabular}{|c|c|c|c|}
\hline$\alpha(x, y)$ & 0 & 1 & 2 \\
\hline 0 & 1 & $\frac{6}{5}$ & $\frac{151}{100}$ \\
\hline 1 & $\frac{6}{5}$ & 1 & $\frac{8}{5}$ \\
\hline 2 & $\frac{151}{100}$ & $\frac{8}{5}$ & 1 \\
\hline
\end{tabular}

and

\begin{tabular}{|c|c|c|c|}
\hline$\mu(x, y)$ & 0 & 1 & 2 \\
\hline 0 & 1 & $\frac{6}{5}$ & $\frac{8}{5}$ \\
\hline 1 & $\frac{6}{5}$ & 1 & $\frac{33}{20}$ \\
\hline 2 & $\frac{8}{5}$ & $\frac{33}{20}$ & 1 \\
\hline
\end{tabular}

The given $q$ is not a controlled metric space for the function $\alpha$. Indeed,

$$
q(0,1)=1>\frac{247}{250}=\alpha(0,2) q(0,2)+\alpha(2,1) q(2,1) .
$$

Choose $T 0=2$ and $T 1=T 2=1$. Set $k=\frac{3}{5}$. It is clear that condition (1) is satisfied. In addition, (2) holds for each $u_{0}$ in X. All hypotheses of Theorem 1 are fulfilled. Here, $\xi=1$ is the unique fixed point.

Example 4. Let $X=[0,4]$. Consider the double controlled metric $q$ and functions $\alpha$ and $\mu$ given in Example 1. Choose $T x=1$ for all $x \in X$. Let $u_{0}=1$ and $k=\frac{1}{2}$. We have

$$
\sup _{m \geq 1} \lim _{i \rightarrow \infty} \frac{\alpha\left(u_{i+1}, u_{i+2}\right)}{\alpha\left(u_{i}, u_{i+1}\right)} \mu\left(u_{i+1}, u_{m}\right)=1<2=\frac{1}{k}
$$

that is, (2) holds. In addition, for each $u \in[0,4]$, we have

$$
\lim _{n \rightarrow \infty} \alpha\left(u, u_{n}\right)=\max (1, u)<\infty \text { and } \lim _{n \rightarrow \infty} \mu\left(u_{n}, u\right)=\max (u, 1)<\infty .
$$

That is, (3) holds. All hypotheses of Theorem 1 are satisfied and $\xi=1$ is the unique fixed point.

Definition 6. Given $u_{0} \in X$, the orbit $O\left(u_{0}\right)$ of $u_{0}$ is defined as $O\left(u_{0}\right)=\left\{u_{0}, T u_{0}, T^{2} u_{0}, \ldots\right\}$, where $T$ is a self-map on the set $X$. The operator $G: X \longrightarrow \mathbb{R}$ is called T-orbitally lower semi-continuous at $\eta \in X$ if when $\left\{u_{n}\right\}$ in $O\left(u_{0}\right)$ such that $\lim _{n \rightarrow \infty} q\left(u_{n}, \eta\right)=0$, we get that $G(\eta) \leq \lim _{n \rightarrow \infty} \inf G\left(u_{n}\right)$.

Proceeding similarly as [17] and using Definition 6, we have the following corollary generalizing Theorem 1 in [24].

Corollary 1. Let $T$ be a self-map on $(X, q)$ a complete double controlled metric type space by two mappings $\alpha, \mu$. Given $u_{0} \in X$. Let $k \in(0,1)$ be such that

$$
q\left(T z, T^{2} z\right) \leq k q(z, T z), \text { for each } z \in O\left(u_{0}\right)
$$

Take $u_{n}=T^{n} u_{0}$ and suppose that

$$
\sup _{m \geq 1} \lim _{i \rightarrow \infty} \frac{\alpha\left(u_{i+1}, u_{i+2}\right)}{\alpha\left(u_{i}, u_{i+1}\right)} \mu\left(u_{i+1}, u_{m}\right)<\frac{1}{k}
$$

Then, $\lim _{n \rightarrow \infty} q\left(u_{n}, \xi\right)=0$. We also we have that $T \xi=\xi$ if and only if the operator $x \mapsto q(x, T x)$ is $T$-orbitally lower semi-continuous at $u$.

Our next fixed point result concerns with the nonlinear case using a control function of Matkowski [25].

Theorem 2. Let $(X, d)$ be a complete double controlled metric type space via two functions $\alpha(x, y)$ and $\mu(x, y)$. Assume that $T: X \rightarrow X$ satisfies for all $x, y \in X$

$$
q(T x, T y) \leq \phi(\Lambda(x, y)), \Lambda(x, y)=\max \{q(x, y), q(x, T x), q(y, T y)\}
$$


where $\phi:[0, \infty) \rightarrow[0, \infty)$ is non-decreasing, continuous and satisfies $\lim _{i \rightarrow \infty} \phi^{i}(s)=0, s>0$. Furthermore, assume that for each $u_{0} \in X$, we have

$$
\sup _{m \geq 1} \lim _{i \rightarrow \infty} \frac{\alpha\left(u_{i+1}, u_{i+2}\right)}{\alpha\left(u_{i}, u_{i+1}\right)} \mu\left(u_{i+1}, u_{m}\right) \frac{\phi^{i+1}\left(q\left(u_{1}, u_{0}\right)\right)}{\phi^{i}\left(q\left(u_{1}, u_{0}\right)\right)}<1,
$$

where $u_{n}=T^{n} u_{0}, \quad n=0,1, \ldots$. If the double controlled metric $d$ and the mapping $T$ are continuous, then there exists a unique fixed point of $T$ (say $\eta$ ) such that for each $u \in X$, we have $T^{n} u \rightarrow \eta$.

Proof. Let $\left\{u_{n}\right\}$ and $u_{0}$ be as in the statement of the theorem. If, for some $m$, we have $u_{m}=u_{m+1}=$ $T u_{m}$, then clearly $u_{m}$ is the fixed point. Now, suppose that $u_{n+1} \neq u_{n}$ for each $n$. From condition (10),

$$
q\left(u_{n}, u_{n+1}\right)=q\left(T u_{n}, T u_{n-1}\right) \leq \phi\left(\Lambda\left(u_{n-1}, u_{n}\right)\right),
$$

where clearly $\Lambda\left(u_{n-1}, u_{n}\right)=\max \left\{q\left(u_{n-1}, u_{n}\right), q\left(u_{n}, u_{n+1}\right)\right\}$. If, for some $n$, we accept that $\Lambda\left(u_{n-1}, u_{n}\right)=q\left(u_{n}, u_{n+1}\right)$, then from (12) and that $\phi(t)<t, \forall t>0$, we have

$$
0<q\left(u_{n}, u_{n+1}\right) \leq \phi\left(q\left(u_{n}, u_{n+1}\right)\right)<q\left(u_{n}, u_{n+1}\right),
$$

which leads to a contradiction. Hence, for all $n$, we must have $\Lambda\left(u_{n-1}, u_{n}\right)=q\left(u_{n-1}, u_{n}\right)$. From which, it follows that $0<q\left(u_{n}, u_{n+1}\right) \leq \phi\left(q\left(u_{n-1}, u_{n}\right)\right)$. If we proceed inductively, we deduce that for each $n \geq 0$, we have

$$
0<q\left(u_{n}, u_{n+1}\right) \leq \phi^{n}\left(q\left(u_{0}, u_{1}\right)\right) .
$$

From the assumption on $\phi$, we conclude that

$$
\lim _{n \rightarrow \infty} q\left(u_{n}, u_{n+1}\right)=0 .
$$

To show that $\left\{u_{n}\right\}$ is Cauchy, we proceed as in the proof of Theorem 1. For all $m>n$, we may get

$$
q\left(u_{n}, u_{m}\right) \leq \alpha\left(u_{n}, u_{n+1}\right) \phi^{n}\left(q\left(u_{0}, u_{1}\right)\right)+\sum_{i=n+1}^{m-1}\left(\prod_{j=0}^{i} \mu\left(u_{j}, u_{m}\right)\right) \alpha\left(u_{i}, u_{i+1}\right) \phi^{i}\left(q\left(u_{0}, u_{1}\right)\right) .
$$

The assumption (11) by means of the ratio test applied to the series derived from the right-hand side of (14), as in the proof of Theorem 1, will lead to the sequence $\left\{u_{n}\right\}$ being Cauchy. Since $(X, d)$ is complete, there exists $\eta \in X$ such that $\lim _{n \rightarrow \infty} q\left(u_{n}, \eta\right)=0$. That $\eta$ is a fixed point is shown as in Remark 2. To prove the uniqueness of the fixed point, assume $z$ is such that $T z=z$ and $z \neq \eta$. By (10), we have

$$
0<q(\eta, z)=q(T \eta, T z) \leq \phi(\Lambda(\eta, z))=\phi(q(\eta, z))<q(\eta, z),
$$

which is a contradiction.

Remark 3. In Theorem 2, if we take $\phi(s)=k s, k \in(0,1)$, then the condition (10) will have the form

$$
q(T x, T y) \leq k \max \{q(x, y), q(x, T x), q(y, T y)\} .
$$

In the following theorem, we propose the related fixed point result of Kannan [26].

Theorem 3. Let $(X, d)$ be a complete double controlled metric type space by the functions $\alpha, \mu: X \times X \rightarrow$ $[1, \infty)$. Let $T: X \rightarrow X$ be a Kannan mapping defined as follows:

$$
q(T x, T y) \leq a[q(x, T x)+q(y, T y)]
$$


for all $x, y \in X$, where $a \in\left(0, \frac{1}{2}\right)$. For $u_{0} \in X$, take $u_{n}=T^{n} u_{0}$. Suppose that

$$
\sup _{m \geq 1} \lim _{i \rightarrow \infty} \frac{\alpha\left(u_{i+1}, u_{i+2}\right)}{\alpha\left(u_{i}, u_{i+1}\right)} \mu\left(u_{i+1}, u_{m}\right)<\frac{1-a}{a} .
$$

For each $u \in X$, assume that

$$
\lim _{n \rightarrow \infty} \alpha\left(u, u_{n}\right) \text { exists, is finite and } \lim _{n \rightarrow \infty} \mu\left(u_{n}, u\right)<\frac{1}{a} .
$$

Then, there exists a unique fixed point of $T$.

Proof. Let $\left\{u_{n}=T u_{n-1}\right\}$ in $X$ be such that the hypotheses (17) and (18) hold. From (16), we obtain

$$
\begin{aligned}
q\left(u_{n}, u_{n+1}\right) & =q\left(T u_{n-1}, T u_{n}\right) \\
& \leq a\left[q\left(u_{n-1}, T u_{n-1}\right)+q\left(u_{n}, T u_{n}\right)\right] \\
& =a\left[q\left(u_{n-1}, u_{n}\right)+q\left(u_{n}, u_{n+1}\right)\right] .
\end{aligned}
$$

Then, $q\left(u_{n}, u_{n+1}\right) \leq \frac{a}{1-a} q\left(u_{n-1}, u_{n}\right)$. By induction, we get

$$
q\left(u_{n}, u_{n+1}\right) \leq\left(\frac{a}{1-a}\right)^{n} q\left(u_{1}, u_{0}\right), \quad \forall n \geq 0 .
$$

Now, let us prove that $\left\{u_{n}\right\}$ is a Cauchy sequence. Using the triangle inequality, for all $n, m \in \mathbb{N}$, we obtain

$$
q\left(u_{n}, u_{m}\right) \leq \alpha\left(u_{n}, u_{n+1}\right) q\left(u_{n}, u_{n+1}\right)+\mu\left(u_{n+1}, u_{m}\right) q\left(u_{n+1}, u_{m}\right) .
$$

Similar to the proof of Theorem 1, we get

$$
\begin{aligned}
q\left(u_{n}, u_{m}\right) & \leq \alpha\left(u_{n}, u_{n+1}\right) q\left(u_{n}, u_{n+1}\right)+\sum_{i=n+1}^{m-2}\left(\prod_{j=n+1}^{i} \mu\left(u_{j}, u_{m}\right)\right) \alpha\left(u_{i}, u_{i+1}\right) q\left(u_{i}, u_{i+1}\right) \\
& +\prod_{k=n+1}^{m-1} \mu\left(u_{k}, u_{m}\right) q\left(u_{m-1}, u_{m}\right) \\
& \leq \alpha\left(u_{n}, u_{n+1}\right)\left(\frac{a}{1-a}\right)^{n} q\left(u_{0}, u_{1}\right)+\sum_{i=n+1}^{m-2}\left(\prod_{j=n+1}^{i} \mu\left(u_{j}, u_{m}\right)\right) \alpha\left(u_{i}, u_{i+1}\right)\left(\frac{a}{1-a}\right)^{i} q\left(u_{0}, u_{1}\right) \\
& +\prod_{i=n+1}^{m-1} \mu\left(u_{i}, u_{m}\right)\left(\frac{a}{1-a}\right)^{m-1} q\left(u_{0}, u_{1}\right) .
\end{aligned}
$$

Since $0 \leq a<\frac{1}{2}$, we have $\frac{a}{1-a} \in[0,1)$ which allows us to proceed as in the proof of Theorem 1 and we deduce that $\left\{u_{n}\right\}$ is a Cauchy sequence in the complete double controlled metric space $(X, d)$. Thus, there exists $u \in X$ as a limit of $\left\{u_{n}\right\}$ in $(X, d)$. Assume that $T u \neq u$. We have

$$
\begin{aligned}
0<q(u, T u) & \leq \alpha\left(u, u_{n+1}\right) q\left(u, u_{n+1}\right)+\mu\left(u_{n+1}, T u\right) q\left(u_{n+1}, T u\right) \\
& \leq \alpha\left(u, u_{n+1}\right) q\left(u, u_{n+1}\right)+\mu\left(u_{n+1}, T u\right)\left[a q\left(u_{n}, u_{n+1}\right)+a q(u, T u)\right] .
\end{aligned}
$$


Passing to the limit on both sides of (20) and making use of the condition (18), we deduce that $0<q(u, T u)<q(u, T u)$, which is a contradiction. Hence, $T u=u$. To prove the uniqueness of the fixed point $u$, suppose that $T$ has another fixed point $v$. Then,

$$
\begin{aligned}
q(u, v)=q(T u, T v) & \leq a[q(u, T u)+q(v, T v)] \\
& =a[q(u, u)+q(v, v)]=0 .
\end{aligned}
$$

Therefore, $u=v$ and $T$ has a unique fixed point.

\section{Remark 4.}

1. Condition (18) in Theorem 3 can be replaced by the continuity of the double controlled metric $d$ and the mapping $T$ as it was done in Theorem 2.

2. Continuity of the double controlled metric $d$ and the mapping $T$ in Theorem 2 can be replaced by the following condition: For each $u \in X$, we have

$$
\lim _{n \rightarrow \infty} \alpha\left(u, u_{n}\right)<\infty \text { and } \lim _{n \rightarrow \infty} \mu\left(u_{n}, T u\right) \phi(q(u, T u))<q(u, T u)
$$

\section{Perspectives}

It is an open question to treat the cases of the related Chatterjea, Hardy-Rogers, Ćirić and Suzuki contraction types. Moreover, it is always of great interest to find real applications for the proven fixed point theorems in metric type spaces. A future work in this direction will be highly recommended.

\section{Conclusions}

Going in the same direction as [23], we initiated the concept of double controlled metric type spaces. We established some fixed point theorems in this setting, namely the related Banach contraction principle, the Matkowski [25] and Kannan [26] type fixed point results. In support of the obtained results, we also provide some examples.

Author Contributions: All authors contributed equally in writing this article. All authors read and approved the final manuscript.

Funding: This work is supported by Prince Sultan University through research Nonlinear Analysis Methods in Applied Mathematics (NAMAM) group number RG-DES-2017-01-17.

Conflicts of Interest: The authors declare no conflict of interest.

\section{References}

1. Bakhtin, I.A. The contraction mapping principle in almost metric spaces. Funct. Anal. 1989, 30, $26-37$.

2. Czerwik, S. Contraction mappings in b-metric spaces. Acta Math. Inform. Univ. Ostra. 1993, 1, 5-11.

3. Abdeljawad, T.; Abodayeh, K.; Mlaiki, N. On fixed point generalizations to partial b-metric spaces. J. Comput. Anal. Appl. 2015, 19, 883-891.

4. Afshari, H.; Atapour, M.; Aydi, H. Generalized $\alpha-\psi$-Geraghty multivalued mappings on $b$-metric spaces endowed with a graph. TWMS J. Appl. Eng. Math. 2017, 7, 248-260.

5. Alharbi, N.; Aydi, H.; Felhi, A.; Ozel, C.; Sahmim, S. $\alpha$-contractive mappings on rectangular $b$-metric spaces and an application to integral equations. J. Math. Anal. 2018, 9, 47-60.

6. Ameer, E.; Arshad, M.; Shatanawi, W. Common fixed point results for generalized $\alpha_{*}-\psi-$ contraction multivalued mappings in b-metric spaces. J. Fixed Point Theory Appl. 2017, 19, 3069-3086. [CrossRef]

7. Aydi, H.; Karapinar, E.; Bota, M.F.; Mitrović, S. A fixed point theorem for set-valued quasi-contractions in b-metric spaces. Fixed Point Theory Appl. 2012, 2012, 88. [CrossRef]

8. Aydi, H.; Bota, M.F.; Karapinar, E.; Moradi, S. A common fixed point for weak $\phi$-contractions on b-metric spaces. Fixed Point Theory 2012, 13, 337-346. 
9. Aydi, H.; Banković, R.; Mitrović, I.; Nazam, M. Nemytzki-Edelstein-Meir-Keeler type results in $b$-metric spaces. Discret. Dyn. Nat. Soc. 2018, 2018, 4745764. [CrossRef]

10. Karapinar, E.; Czerwik, S.; Aydi, H. $(\alpha, \psi)$-Meir-Keeler contraction mappings in generalized b-metric spaces. J. Funct. Spaces 2018, 2018, 3264620. [CrossRef]

11. Mlaiki, N.; Mukheimer, A.; Rohen, Y.; Souayah, N.; Abdeljawad, T. Fixed point theorems for $\alpha-$ $\psi$-contractive mapping in $S_{b}$-metric spaces. J. Math. Anal. 2017, 8, 40-46.

12. Roshan, J.R.; Parvaneh, V.; Sedghi, S.; Shobkolaei, N.; Shatanawi, W. Common fixed points of almost generalized $(\psi, \varphi)_{s}$-contractive mappings in ordered b-metric spaces. Fixed Point Theory Appl. 2013, 2013, 159. [CrossRef]

13. Shatanawi, W. Fixed and common fixed point for mapping satisfying some nonlinear contraction in $b$-metric spaces. J. Math. Anal. 2016, 7, 1-12.

14. Shatanawi, W.; Pitea, A.; Lazovic, V. Contraction conditions using comparison functions on b-metric spaces. Fixed Point Theory Appl. 2014, 2014, 135. [CrossRef]

15. Souayah, N.; Mlaiki, N.; Mrad, M. The $G_{M}$-contraction principle for mappings on $M-$ metric spaces endowed with a graph and fixed point theorems. IEEE Access 2018, 6, 25178-25184. [CrossRef]

16. Souayah, N.; Mlaiki, N. A fixed point theorem in $S_{b}$ metric spaces. J. Math. Comput. Sci. 2016, 16, 131-139. [CrossRef]

17. Kamran, T.; Samreen, M.; Ain, Q.U.L. A Generalization of b-metric space and some fixed point theorems. Mathematics 2017, 5, 1-7. [CrossRef]

18. Abdeljawad, T. Meir-Keeler $\alpha$-contractive fixed and common fixed point theorems. Fixed Point Theory Appl. 2013, 2013, 19. [CrossRef]

19. Ansari, A.H.; Aydi, H.; Kumari, P.S.; Yildirim, I. New fixed point results via C-class functions in $b$-rectangular metric spaces. Commun. Math. Anal. 2018, 9, 109-126.

20. Mustafa, Z.; Jaradat, M.M.M.; Aydi, H. A. Alrhayyel, Some common fixed points of six mappings on $G_{b}-$ metric spaces using (E.A) property. Eur. J. Pure Appl. Math. 2018, 11, 90-109. [CrossRef]

21. Patel, D.K.; Abdeljawad, T.; Gopal, D. Common fixed points of generalized Meir-Keeler $\alpha$-contractions. Fixed Point Theory Appl. 2013, 2013, 260. [CrossRef]

22. Huang, H.; Deng, G.; Radevovic, S. Fixed point theorems in b-metric spaces with applications to differential equations. J. Fixed Point Theory Appl. 2018. [CrossRef]

23. Mlaiki, N.; Aydi, H.; Souayah, N.; Abdeljawad, T. Controlled metric type spaces and the related contraction principle. Mathematics 2018, 6, 194. [CrossRef]

24. Hicks, T.L.; Rhodes, B.E. A Banach type fixed point theorem. Math. Jpn. 1979, 24, 327-330.

25. Matkowski, J. Fixed point theorems for mappings with a contractive iterate at a point. Proc. Am. Math. Soc. 1977, 62, 344-348. [CrossRef]

26. Kannan, R. Some results on fixed points. Bull. Calcutta Math. Soc. 1968, 60, 71-76.

(C) 2018 by the authors. Licensee MDPI, Basel, Switzerland. This article is an open access article distributed under the terms and conditions of the Creative Commons Attribution (CC BY) license (http:/ / creativecommons.org/licenses/by/4.0/). 